\title{
Peak Expiratory Pressure
}

National Cancer Institute

\section{Source}

National Cancer Institute. Peak Expiratory Pressure. NCI Thesaurus. Code C120938.

The maximum amount of pressure applied to the lungs during expiration. 